\title{
Metabolic discrimination of pine resins using multiple analytical platforms
}

\author{
Luis Francisco Salomé-Abarca ${ }^{\mathrm{a}}$, Jorik van der Pas ${ }^{\mathrm{a}}$, Hye Kyong Kim ${ }^{\mathrm{a}}$, Gerda A. van Uffelen ${ }^{\mathrm{b}}$, \\ Peter G.L. Klinkhamer ${ }^{\mathrm{c}}$, Young Hae Choi ${ }^{\mathrm{a}, \mathrm{d}, *}$ \\ a Natural Products Laboratory, Institute of Biology, Leiden University, Sylviusweg 72, 2333 BE Leiden, The Netherlands \\ ${ }^{\mathrm{b}}$ Hortus Botanicus, Rapenburg 73, 2311 GJ Leiden, The Netherlands \\ c Plant Ecology and Phytochemistry, Institute of Biology, Leiden University, Sylviusweg 72, 2333 BE Leiden, The Netherlands \\ d College of Pharmacy, Kyung Hee University, 02447 Seoul, Republic of Korea
}

\section{A R T I C L E I N F O}

\section{Keywords:}

\section{Pine resin}

Metabolic variation

Terpenoids

HPTLC

NMR

GC-MS

\begin{abstract}
A B S T R A C T
Resins are one of the first sites of interaction between plants and biotic and abiotic factors. Despite their evident morphological and chemical differentiation from other plant organs, the detailed correlation between resins and biological or environmental factors is not yet clear. In this study, ${ }^{1} \mathrm{H}$ nuclear magnetic resonance (NMR), gas chromatography coupled with mass spectrometry (GC-MS) and high-performance thin-layer chromatography (HPTLC)-based profiling techniques were applied to the metabolic characterisation of plant resins of different species and season of collection, using samples from five different species that were collected during early and late spring. The ${ }^{1} \mathrm{H}$ NMR analysis confirmed the main metabolic groups in the resins to be terpenoids and further GC-MS analysis revealed a notable chemical variation between the species and collection periods. Abies grandis displayed a significant differentiation from the other species, showing a higher number of monoterpenes. The HPTLC-based profiling method hyphenated with multivariate data analysis (MVDA) also showed a clear separation confirming the GC-MS terpenoidal profiling results. Additionally, the unknown compounds were obtained by preparative TLC for identification. Based on the results of the three analytical platforms, it was concluded that the major difference in chemical composition of pine species was between species rather than the collection period. Nonetheless, the chemical profiles of resins from different species and collection periods can be well discriminated and correlated to mono- and sesquiterpenes in the case of species and diterpenes for the collection periods.
\end{abstract}

\section{Introduction}

Plant resins have been used in traditional medicine for many years and have commercial value (Dell and McComb, 1979). Though there is some information on their herbivore insect repelling efficiency, their full physiological and biological functions in plants require deeper investigation. These activities are probably related to their toxicity or their role as signal molecules that attract specific predators or parasitoids (Price et al., 1980; Raffa and Berryman, 1983; Mumm et al., 2003).

Plant resins contain a diverse array of specialised metabolites, including terpenes and phenolic compounds. Amongst these terpenes, there are roughly equal amounts of monoterpenes and diterpenes and a smaller fraction of sesquiterpenes and triterpenes (Phillips and Croteau, 1999; Martin et al., 2002). The characterisation of resins has progressed greatly over the years thanks to the development of sophisticated molecular and chemical technologies that are now accessible for their analysis.

Recently, diverse metabolomics tools have been applied to the research of resin chemistry and physiology. Amongst these, a study that combined gas chromatography coupled with mass spectrometry (GCMS) followed by statistical analysis of the data showed that monoterpenes could affect the spread of the invasive mountain pine beetle, Dendroctonus ponderosae (Taft et al., 2015). This finding coincided with the results of a study on the variation in the chemical composition of pines with different herbivory levels, using a similar approach (Keefover-Ring and Linhart, 2010). Liquid chromatography coupled with mass spectrometry (LC-MS)-based metabolomics has been used to establish whether the responses to folivores in closely related plant species could be associated with macroevolutionary traits and plantfolivore coevolutionary processes (Rivas-Ubach et al., 2016).

Due to the complexity of the metabolome, one single analytical method is generally insufficient to cover all types of metabolites. It is for this reason that the use of multiple protocols and analytical

\footnotetext{
* Corresponding author. Natural Products Laboratory, Institute of Biology, Leiden University, Sylviusweg 72, 2333 BE Leiden, The Netherlands.

E-mail address: y.choi@chem.leidenuniv.nl (Y.H. Choi).
} 


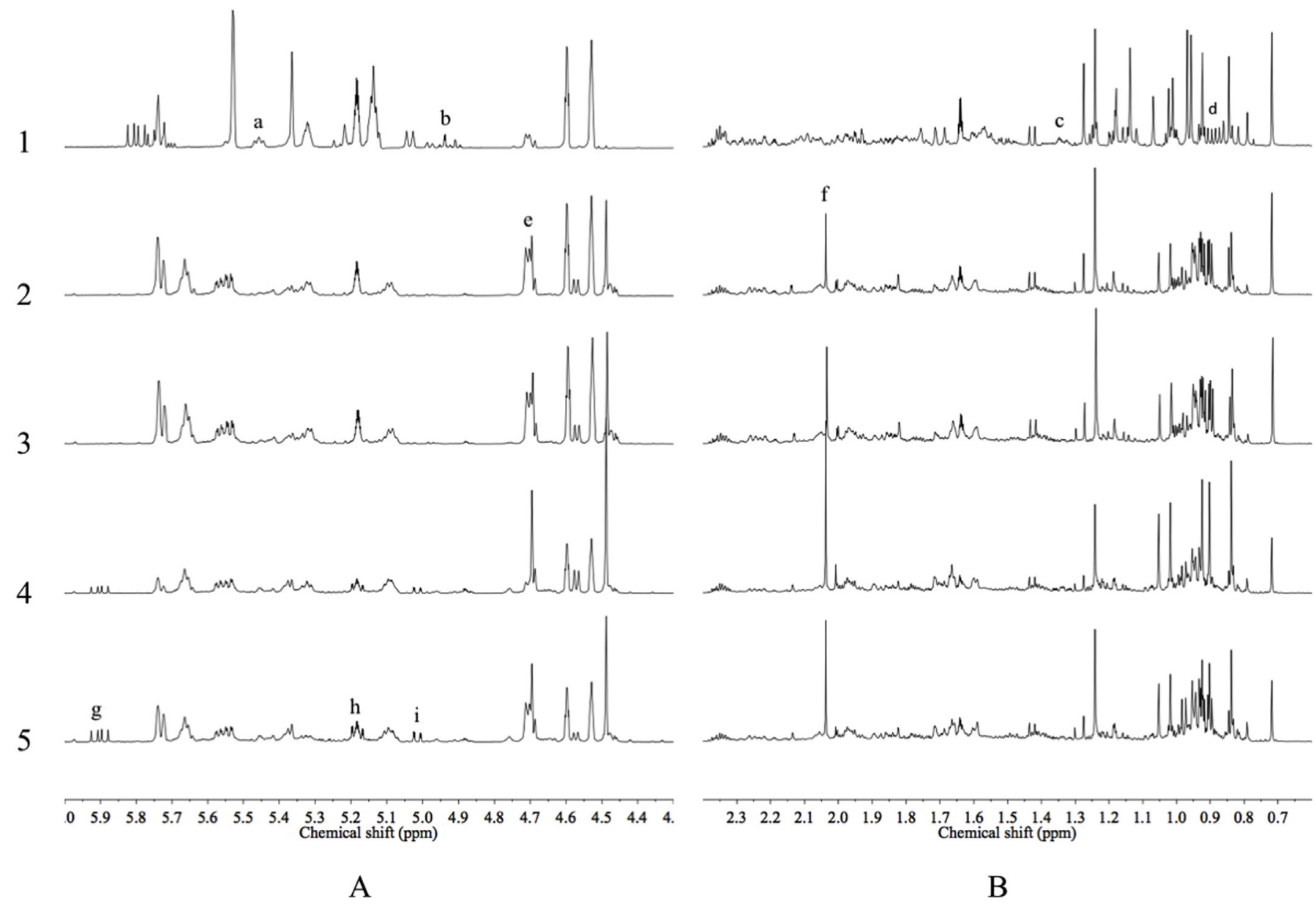

Fig. 1. Typical ${ }^{1} \mathrm{H}$ NMR ( $600 \mathrm{MHz}$ in $\mathrm{CH}_{3} \mathrm{OH}-\mathrm{d}_{4}$ ) spectra of pine resins in the range of $\delta 4.3-\delta 6.0$ (A) and d 0.6-2.4 (B). 1: Abies grandis, 2: Pseudotsuga menziesii, 3 : Picea abies, 4: Pinus sylvestris, 5: Pinus strobus. a: H-3 of $\alpha$-pinene, b: H-10a and H-10b of $\beta$-pinene, c: H-9 of $\alpha$-pinene, d: H-8 of $\alpha$-pinene, e: H-2 from bornyl acetate, f: $\mathrm{CH}_{3} \mathrm{CO}-$ of bornyl acetate, g: $\mathrm{H}-15 \mathrm{~b}$ from sclareol, h: H-14 from sclareol, i: $\mathrm{H}-15 \mathrm{a}$ from sclareol.

instruments is necessary to obtain truly comprehensive information (Gromski et al., 2015).

For untargeted metabolic analysis, there are various analytical platforms that can be used, including both stand-alone or hyphenated systems. Among the existing analytical technology, nuclear magnetic resonance spectroscopy (NMR)- and mass spectrometry (MS)-based methods are currently the most popular analytical tools for metabolomics, since the data they can provide, fulfils the essential requirements for these studies, i.e., the detection of a broad chemical range of metabolites with adequate resolution and sensitivity. Though both methods have advanced greatly in recent years their individual strengths and limitations in terms of metabolite coverage, resolution and sensitivity prevail and each method has a specific target range of metabolites for which its response is optimum. Hence, hyphenated platforms are essential to obtain the most comprehensive information on the metabolome. Amongst the recently introduced systems, thinlayer chromatography (TLC) has shown an interesting potential as a complementary tool for metabolomics.

Thin-layer chromatography, a type of planar chromatography, has several advantages as an analytical tool, such as a short overall measuring time considering that it allows simultaneous analysis of multiple samples, a high signal robustness and requires a relatively low initial investment in equipment and running costs compared to other chromatographic methods (Morlock et al., 2014). Amongst all of the advantages of TLC, the broadness of the range of detectable metabolites is regarded to be its strongest feature as a tool for metabolomics. Many groups of metabolites can be selectively visualised using numerous chemical derivatisation methods (Fichou et al., 2016). Moreover, when used preparatively, TLC bands can be easily separated for further analyses or bioactivity tests. In view of the evident potential of TLC, it is worth reopening the debate as to whether it may be a realistic option that can compensate for the limitations of current NMR- or MS-based metabolomics methods.

When considering TLC as a metabolomics tool, it is important to be aware of inherent features such as its low resolution and reproducibility. However, throughout the last decade, great efforts have been made to improve these limitations, and the development of highly efficient sorbents has resulted in a greatly increased resolution. Additionally, other technological advances focussed on a full automation of all steps required for a TLC analysis, such as sample application, development and chemical derivatisation have increased the robustness of TLC as a profiling method. This advanced version of TLC, known as high-performance thin-layer chromatography (HPTLC), has been successfully used as a fingerprinting tool in metabolomics (Nicoletti et al. 2012; Nicoletti, 2012; Nicoletti et al. 2013a).

Added to these technological improvements in TLC hardware and resolution, the development of better methods for the processing of TLC-generated data has also been achieved, converting this method in a robust tool for metabolic profiling. This is the case of an efficient data processing tool that has recently been developed and applied to MVDA by Fichou et al. (2016).

The aim of this study was to investigate the profiles of pine resins collected from five species of the Pinaceae family, Abies grandis Douglas ex D.Don Lindl. (Pinaceae), Pseudotsuga menziesii (Mirb.) Franco 

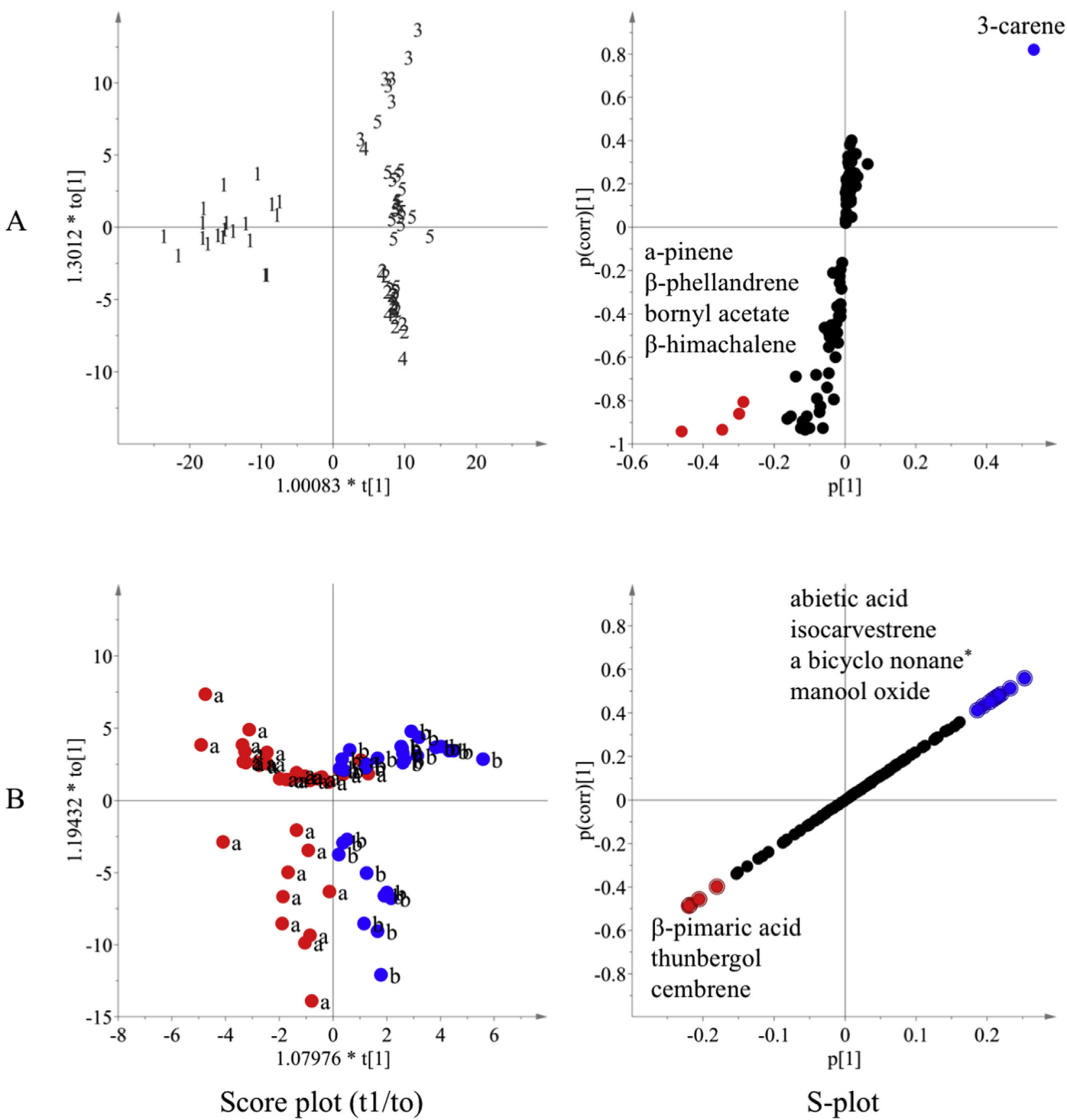

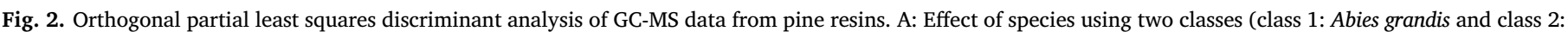

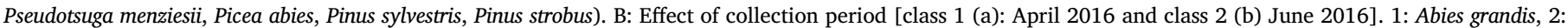
Pseudotsuga menziesii, 3: Picea abies, 4: Pinus sylvestris, 5: Pinus strobus. * 6-ethenyl-6,9,9trimethyl-4-methylidenebicyclo[5.2.0]nonane.

(Pinaceae), Picea abies (L.) H. Karst. (Pinaceae), Pinus sylvestris L. (Pinaceae) and Pinus strobus L. (Pinaceae), throughout two different collection periods, early and late spring (April/June 2016). This was done using conventional metabolomics tools, ${ }^{1} \mathrm{H}$ NMR and GC-MS, that were supplemented with an HPTLC method. The results from the three analytical platforms were compared in terms of the separation of samples and identification capacity. The results revealed an interesting potential of HPTLC as a tool for metabolomics.

\section{Results and discussion}

To investigate the effect of variations amongst species and different environmental conditions, resin samples were selected from representative subfamilies of the Pinaceae family according to a previous classification (Price et al., 1980) and then collected in two different months (April and June 2016). The months that were chosen for sample collection correspond to early and late spring that could differ in a number of ecological interactions, that could be reflected in the metabolome of the resins.

The resulting 68 resin samples were firstly analysed by ${ }^{1} \mathrm{H}$ NMR. The spectra showed that the major signals corresponded to terpenoid-like compounds (Fig. 1). Many aliphatic signals of these compounds were overlapped but some characteristic methyl, aliphatic methylene and methine proton signals were identified in the ranges of $\delta 4.4-\delta 5.5$ (Fig. 1A) and $\delta 0.6-\delta 1.4$ (Fig. 1B). The singlets at $\delta 0.84$ and $\delta 1.27$ were assigned to the H-9 and H-8 of the methyl protons in the cyclobutane ring of $\alpha$-pinene. Alongside these methyl signals, some distinctive olefinic protons were also detected, e.g., $\mathrm{H}-3$ resonance at $\delta$ 
$5.42(\mathrm{t}, J=7.1 \mathrm{~Hz}$ ) of $\alpha$-pinene, $\mathrm{H}-10 \mathrm{a}$ and $\mathrm{H}-10 \mathrm{~b}$ of $\beta$-pinene at $\delta 4.90$ (d, $J=1.4 \mathrm{~Hz}$ ) and $\delta 4.95(\mathrm{~d}, J=1.4 \mathrm{~Hz})$. The signals at $\delta 4.71(\mathrm{~d}$, $J=6.2 \mathrm{~Hz}$ ) and $\delta 2.03$ (s) were assigned to the $\mathrm{H}-2$ and acetyl group of bornyl acetate, respectively. Additionally, three typical doublets at $\delta$ 5.89 (dd, $J=17.3 \mathrm{~Hz}, 10.8 \mathrm{~Hz}$ ), $\delta 5.18$ (overlapped with other signals) and $\delta 5.01$ (dd, $J=10.8,1.5$ ) were assigned to the H15b, H-14 and H$15 \mathrm{a}$ of sclareol by comparison to with a reference compound.

In the first place, principal component analysis (PCA) was applied to monitor the influence of the two factors, i.e., species and collection period, on the overall metabolome. As PCA showed no clear separation between the species and collection periods, orthogonal partial least squares discriminant analysis (OPLS-DA) was applied as the next approach. However, the prediction power of the generated OPLS-DA model for the species effect was not validated as the cross-validation $Q^{2}$ value was low $(<0.30)$. Moreover, there was no significant effect on the CV-ANOVA test $(p>0.05)$. In the case of the collection period, the OPLS-DA model was not validated either $\left(Q^{2}<0.30\right.$ and $p>0.05$ in CV-ANOVA).

${ }^{1} \mathrm{H}$ NMR-based profiling is one of the most popular metabolomic profiling techniques, used mostly for broad ranges of metabolite groups. However, in the spectra of the pine resins, most of the metabolites were found to be terpenoids, that present highly congested ${ }^{1} \mathrm{H}$ NMR resonances and these overlapping signals hindered the resolution of individual terpenoids. Unlike ${ }^{1} \mathrm{H}$ NMR, ${ }^{13} \mathrm{C}$ NMR has proved to be successful in studies involving similar metabolites such as Scotch pine balsams (Skakovskii et al., 2008). However, issues such as its low quantitative accuracy and extended measuring time conspire against its applicability.

Based on the profiling results obtained with ${ }^{1} \mathrm{H}$ NMR that showed resins to be terpenoid-rich, GC-MS was selected as the most suitable analytical tool due to its reproducibility and robustness for terpenoid analysis (Witte, 1986; Taft et al., 2015). The identified GC-MS peaks (total ion current of 190 identified compounds) were treated as variables and their areas were normalised with an internal standard ( $200 \mu \mathrm{g} / \mathrm{mL}$ of tetradecane) after applying a peak-picking method (Koek et al., 2011).

The data obtained with GC-MS allowed a clearly noticeable metabolic discrimination amongst the five species. In particular, A. grandis resins were well distinguished from all other species in the PCA results (Supplementary Fig. 1). To identify the discriminating metabolites, OPLS-DA was employed using two classes (class 1: Abies grandis and class 2: Pseudotsuga menziesii, Picea abies, Pinus sylvestris and Pinus strobus) giving a highly validated separation $\left(Q^{2}=0.91\right)$ (Fig. $\left.2 \mathrm{~A}\right)$. The S-plot showed high levels of $\alpha$-pinene, $\beta$-phellandrene, bornyl acetate and $\beta$-himachalene in $A$. grandis resins, but the lowest levels of 3-carene among all tested species (Fig. 2A).

To investigate the effect of the seasonal variation, samples were collected in two different months (April/June 2016). These samples were analysed with the expectation that the resin metabolic pool could reflect the environmental differences between these months. The effect of the different species was suppressed by using OPLS-DA with two classes: (a): April; (b): June (Fig. 2B). The effect of the collection time appeared to be less distinguished than the species. When the Pareto scaling method was applied to the data set, the separation was not adequately validated $\left(Q^{2}=0.12\right.$ and $p$ value in CV-ANOVA $\left.=0.23\right)$. This was possibly due to the interference of the larger variation between the species. To reduce this interference, a unit-variance scaling method was applied to the same data set instead of the Pareto scaling method. As shown in Fig. 2B, a clear distinction between the two different months was now obtained with an increased $Q^{2}$ value $(0.34)$ and a highly significant $p$-value in CV-ANOVA $\left(3.02 \times 10^{-5}\right)$. In the samples collected in June, a higher level of abietic acid, isocarvestrene and manool oxide, as well as a bicyclo nonane analogue, were found. Conversely, the concentrations of $\beta$-pimaric acid, thunbergol and cembrene were lower.

It is generally assumed that the chemical outcome in the resins is more associated with environmental factors than other tissues in the producing plants such as leaves or stems. It is well known that the levels of terpenoids, particularly in plant exudates, can be affected by environmental factors. For example, the seasonal variation of the chemical composition of the essential oils extracted from Inga laurina, Croton heliotropiifolius, and Cordia verbenacea was proved to be strongly correlated with their antimicrobial activity (Furtado et al., 2014; De Alencar Filho et al., 2017; Matias et al., 2016).

Although GC-MS metabolic profiling analysis provides detailed information on targeted groups of metabolites (i.e., terpenoids in this study), it has its limitations in the identification of unknown metabolites. In many cases, MS is not sufficient to confirm the chemical structures of identified peaks, particularly for isomers. Actually, over half the peaks remain unidentified in GC-MS metabolomics analyses due either to the lack of reference compounds or the absence of fragmentation patterns in the library (Kusano et al., 2015). The use of highresolution MS technology or subsequent $\mathrm{MS}^{\mathrm{n}}$ analysis can greatly circumvent these limitations but even then, many peaks remain unidentified (Kohyama et al., 2016; Kusano et al., 2015). This prompted us to combine results from the different analytical platforms, complementing the information obtained from each one.

High-performance thin-layer chromatography is expected to be a good candidate as a supplementary profiling tool. Its wide detection range and preparative capability that allows the separation of compounds for further isolation can provide important benefits for a metabolomics study. Fig. 3 shows an HPTLC chromatogram of the pine resins investigated in this study. The optimised HPTLC conditions for terpenoid analysis included the use of normal phase silica gel plates and the chemical derivatisation with anisaldehyde- $\mathrm{H}_{2} \mathrm{SO}_{4}$ for the visualisation of terpenoids under UV $366 \mathrm{~nm}$. Confirming the ${ }^{1} \mathrm{H}$ NMR and GCMS results, the main metabolites in the pine resins were found to be terpenoids.

Chemical fingerprinting is often performed with HPTLC, botanical samples being some of the best examples (Gallo et al., 2013; Toniolo et al., 2014). The complex chemical composition that is revealed on HPTLC plates has been used to profile data sets (Nicoletti et al., 2013b) which can be visually inspected and evaluated using MVDA.

To perform MVDA with HPTLC generated data, the intensity of each $\mathrm{R}_{\mathrm{f}}$ value of all the samples was normalised by the QC sample in order to minimise the variation of the replicates on different plates and improve the quality of the analysis (Liu et al., 2018). An external QC sample (pooled extract) was spotted alongside the other samples on each plate. After the normalisation process, the recently-developed open-source

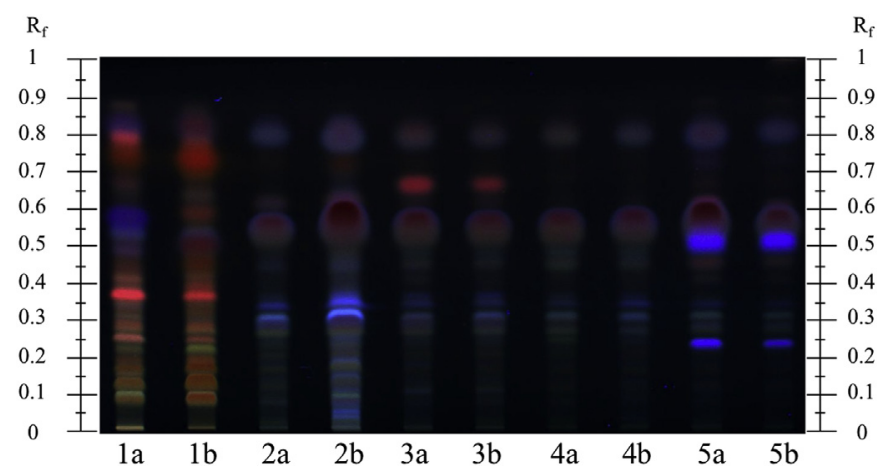

Fig. 3. Typical high-performance thin-layer chromatograms (HPTLC) chromatogram of the resins analysed in this study developed on silica gel HPTLC plates $\left(20 \times 10 \mathrm{~cm}, \mathrm{~F}_{254}\right)$ using tol-IPA-Et $\mathrm{H}_{2} \mathrm{O}(16: 1: 3, \mathrm{v} / \mathrm{v} / \mathrm{v})$ as the mobile phase. Plates were sprayed with anisaldehyde- $\mathrm{H}_{2} \mathrm{SO}_{4}$ and viewed at $366 \mathrm{~nm}$. Species/ collection date; 1a: Abies grandis/April 2016, 1b: Abies grandis/June 2016, 2a: Pseudotsuga menziesii/April 2016, 2b: Pseudotsuga menziesii/June 2016, 3a: Picea abies/April 2016, 3b: Picea abies/June 2016, 4a: Pinus sylvestris/April 2016, 4b: Pinus sylvestris/June 2016, 5a: Pinus strobus/April 2016, 5b: Pinus strobus/June 2016. 


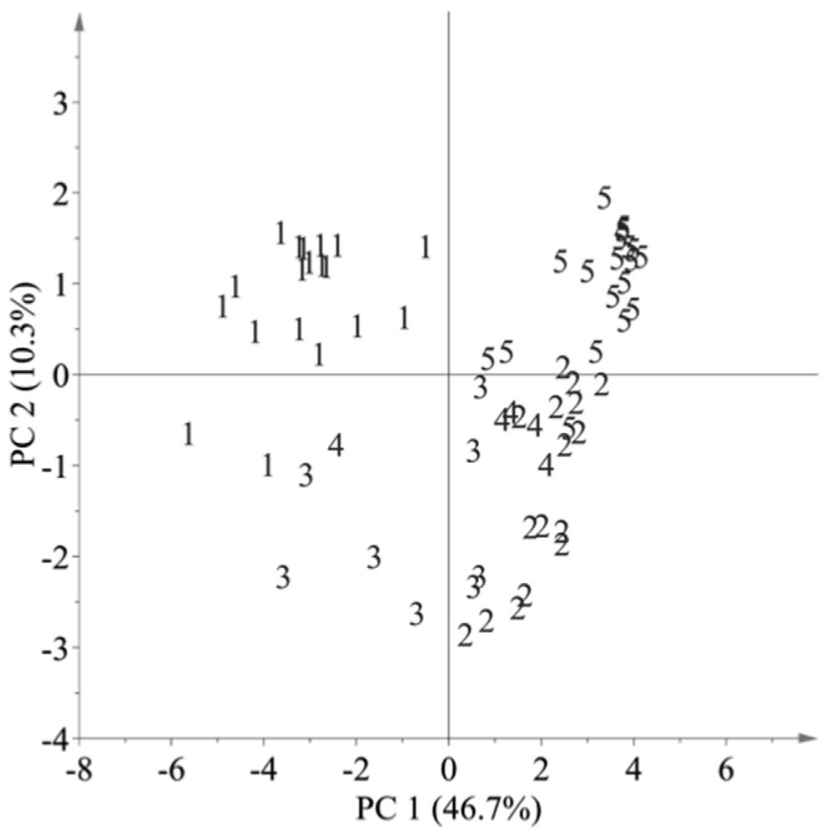

A

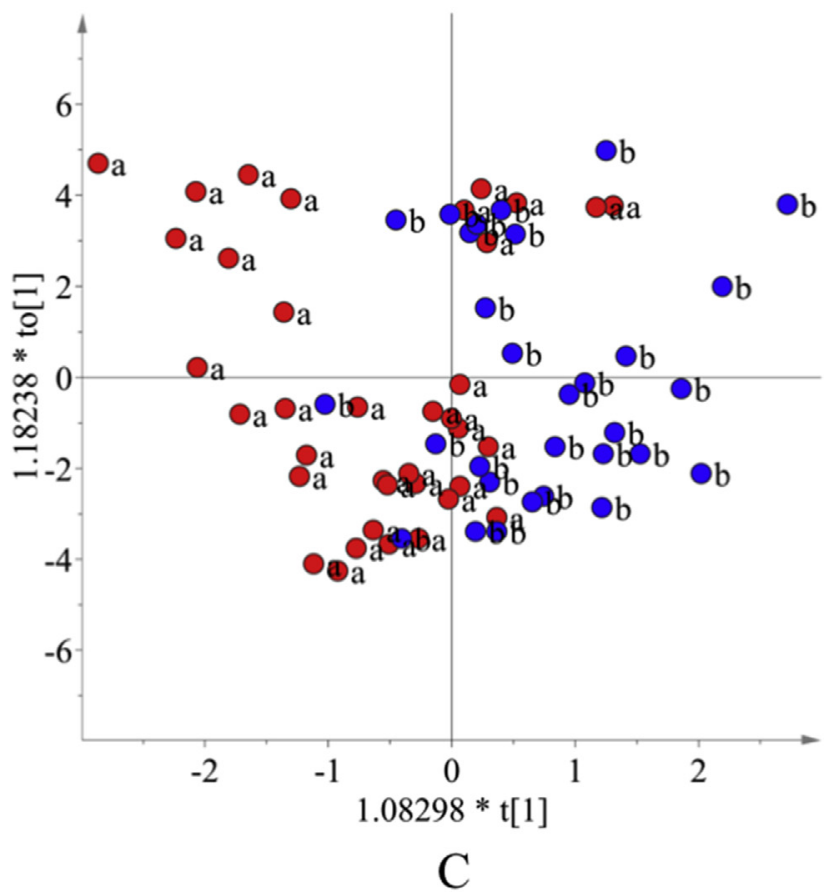

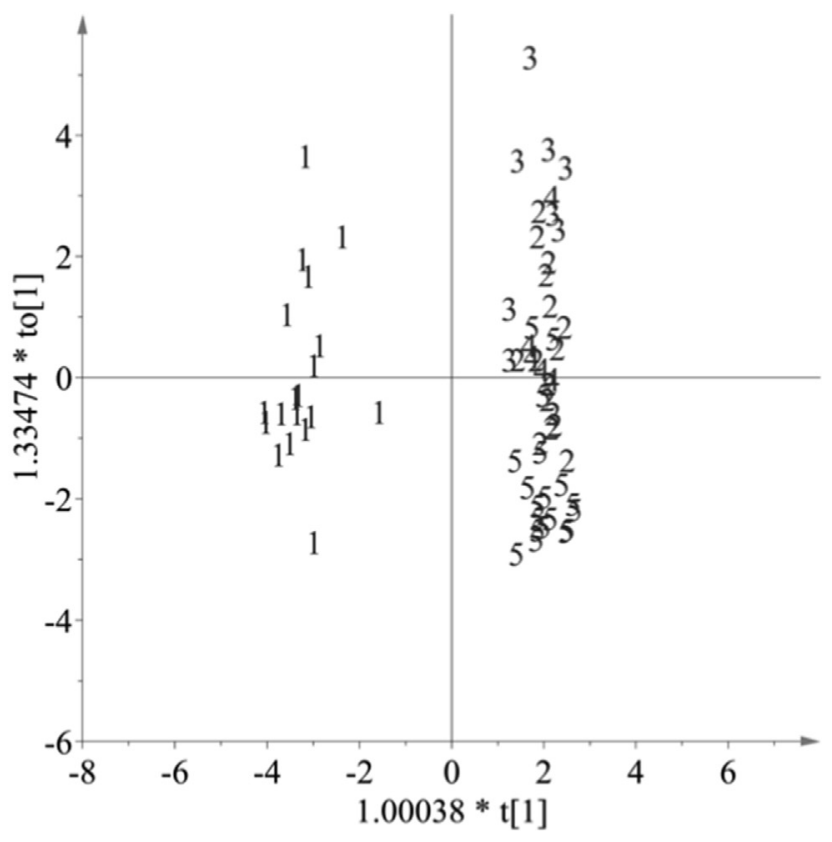

B

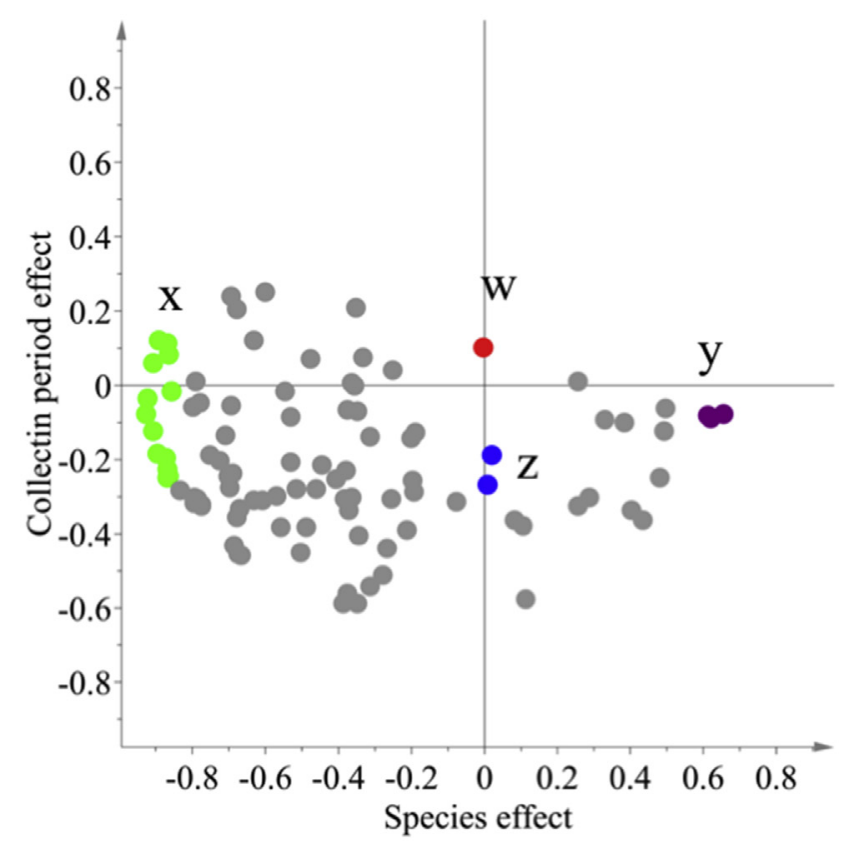

D

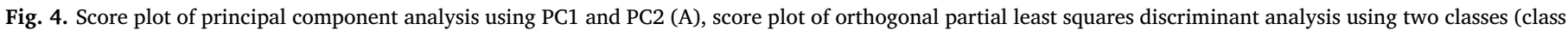

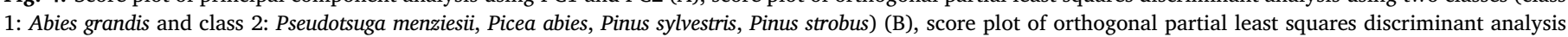

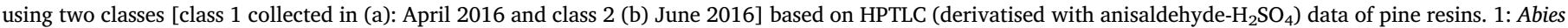

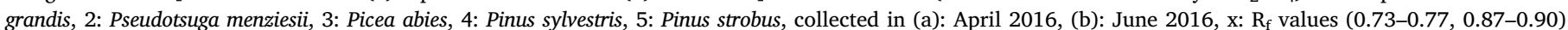

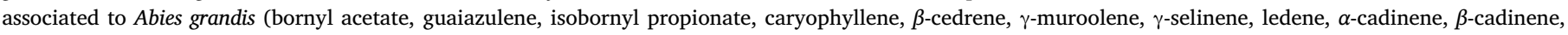

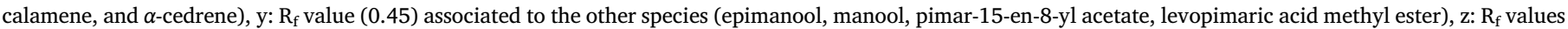

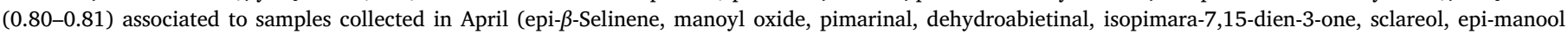
oxide, hibaene), $\mathrm{w}$ : $\mathrm{R}_{\mathrm{f}}$ value (0.49) associated to samples collected in June (biformene, isopimaric acid, pimara-7,15-dien-3-ol, $\beta$-pimaric acid).

software, rTLC, was used for alignment. This offers a standardised procedure for the image processing and visualisation tools that are required to compare HPTLC fingerprints via different pattern recognition and prediction techniques (Fichou et al., 2016). Fig. 4 shows the results of PCA and OPLS-DA applied to the HPTLC data. In the score plot of PCA, the resins of $A$. grandis were clearly differentiated from the resins of the other species (Fig. 4A). This was investigated in detail via OPLSDA using two classes; class 1: A. grandis, and class 2: P. menziesii, $P$. abies, $P$. sylvestris and $P$. strobus. The HTPLC PCA and OPLS-DA results were very similar to those obtained with GC-MS data (Fig. 4B).

The separation obtained between the two groups collected in different collection periods using HPTCL-based profiling did not reveal as 
much as GC-MS profiling ( $Q^{2}$ value, 0.18$)$ though a potential differentiation in HPTLC was obtained since the $p$-value in CV-ANOVA was $<0.05$. Two OPLS-DA models (species and collection period) were merged using a shared and unique structures (SUS)-plot in order to distinguish the metabolites by each factor. In this plot, diagonallyaligned metabolites are of equal importance and are shared by the two investigated models, and the main factor influencing the intensity of the spot can be deduced (Fig. 4D). In the SUS-plot, the effects of the individual factors (X-axis for species and $\mathrm{Y}$-axis for collection period) were plotted to organise the metabolites by each factor.

The bands $\left(R_{f}\right.$ 0.73-0.77 and $R_{f}$ 0.87-0.90) in the SUS-plot were found to be highly concentrated in A. grandis, while the bands with $\mathrm{R}_{\mathrm{f}}$ 0.44 and $R_{f} 0.45$ were found to be more concentrated in the other species (Fig. 4D). Although the effect of the collection period was evidently lower than that of the species, two groups of bands showed clear variations. One band $\left(R_{f} 0.49\right)$ was mainly influenced by the collection period and was found to be stronger in the samples that were collected in June 2016. The other two HPTLC bands of $R_{f} 0.80$ and $R_{f} 0.81$ were more intense in the samples obtained in April 2016 (Fig. 3).

The selected bands were obtained using prep-TLC and analytical HPTLC to be further analysed by GC-MS. The band with $R_{f} 0.49$, which was more concentrated in the samples collected in June 2016, contained a mixture of diterpenes (Fig. 3). Thus, for the samples collected during this period, the species had a larger effect on the chemical composition of pine resins rather than the collection periods. We can assume that the chemical composition in pine resins from early spring to late spring is altered due to the change of environmental conditions. However, in previous reports it was reported that the monoterpene emission profile $P$. sylvestris was almost constant throughout autumn and spring. For example, it was found that the level of $\Delta 3$-carene, a major monoterpene of $P$. sylvestris resin, is not affected by time but rather by species (Hakola et al., 2006). Monoterpenes and sesquiterpenes are significant discriminating compounds among the different species. However, diterpenes tend to be related to the collection period. Among the plausible explanations for the seasonal difference in the metabolic profile of resins it is important to note that in the pines, the maximum emission of sesquiterpene compounds has been observed to coincide with a high concentration of spores from pathogenic microorganisms in the air, suggesting a potential defensive role of the volatile emissions (Hakola et al., 2006). At the beginning of spring, natural populations begin to grow and airborne pathogens are the first to interact with potential hosts. This means that the chemical defense systems in the susceptible plants will be focussed on aerial invaders, a task most suited for volatile compounds. These microorganisms, however, are not the only threat to plants in general and pine trees are no exception. Unlike spores, insects can detect volatile compounds to locate their hosts reaching plants not only by air but also via terrestrial invasion. As a result, metabolites that are on surfaces of contact will be more suitable components of plant defence systems once the volatile barrier has been surpassed by the invading organisms. The results of this study would fit in with this scenario, especially considering that diterpenes, known to have cytotoxic effects and act as insect deterrents, were responsible for the effect of seasonal variations coinciding with the increase in herbivore populations. A similar pattern had been observed when studying the relationship between the terpenoid composition and cone insect distribution in the seed cones of Ponderosa pines, using a classical approach. Negative correlations were found between cone insect herbivory levels and mono- and diterpene factors at one site, indicating that the presence of these herbivores could partially explain the levels of chemical flux observed in these pines (KeefoverRing and Linhart, 2010).

Another remarkable result of this study, was the detection and identification by HPTLC- metabolomics of metabolites that had not been previously detected as discriminants by GC-MS analysis. This included compounds such as isobornyl propionate, ledene, copaene, calamene, $\alpha$-cubebene, $\alpha$-cedrene, $\beta$-cedrene, $\gamma$-muroolene, $\gamma$-selinene, sclareol and other diterpenic acids (Fig. 3). As previously discussed, the ecological interactions between pine resin compounds and pathogens or herbivores have been extensively studied. However, only a few compounds such as $\alpha$ - or $\beta$-pinene, carene isomers and other volatiles have been identified. The investigation of the effect of species, geographical distribution, or pathogens relationships of pines should be separately performed to detect and understand these biochemical phenomena. Undoubtedly, the implementation of a more sensitive and multi-detection approach can provide new and accurate information that will allow a deeper insight into chemical ecology interactions and mechanisms that could result in their eventual application to other scientific fields.

\section{Conclusions}

The effect of the species and collection period on the metabolic profile of pine resins was studied using two main analytical platforms, ${ }^{1} \mathrm{H}$ NMR and GC-MS. Initially, ${ }^{1} \mathrm{H}$ NMR was used for the overall metabolic profiling but due to signal congestions, the samples were not clearly separated by species or collection period. Considering that the major metabolites detected were terpenoids, GC-MS was selected as a second analytical platform, and a clear separation by species and collection period was obtained. Both groups of resin samples showed unique terpenoidal patterns which is in agreement with previous hypotheses related to the defensive nature of resins. This is supported by differences between the collection periods, which may be due to the environmental changes.

To broaden the detectable range of metabolites, HPTLC was applied to the same set of samples, taking advantage of its interesting features as a metabolic profiling tool. These include the possibility of performing simultaneous multi-sample analysis, the detection of a wide range of metabolites when combined with chemical derivatisation and the ease of preparative separation to obtain unknown compounds for their identification. Most of the metabolites detected in GC-MS were confirmed by HPTLC analysis. The results showed that while variations both in the species and season of collection affected the metabolomic profile, it was the species that caused most noticeable variations. In the case of the species, the discriminant metabolites were mono- and sesquiterpenes, while diterpenes were related to the period of collection. The use of multi-window metabolite separation, detection and identification is encouraging for the study of chemical ecology interactions between plant chemical production and biotic factors, such as pathogens or herbivores.

\section{Experimental}

\subsection{Sample collection}

Pine resins were collected from the following species: Abies grandis Douglas ex D. Don Lindl. (Pinaceae) (Voucher specimen for resin No. NPL-RE-20160521-1), Pseudotsuga menziesii (Mirb.) Franco (Pinaceae) (Voucher specimen for resin No. NPL-RE-20160521-2), Picea abies (L.) H. Karst. (Pinaceae) (Voucher specimen for resin No. NPL-RE20160521-3), Pinus sylvestris L. (Pinaceae) (Voucher specimen for resin No. NPL-RE-20160521-4) and Pinus strobus L. (Pinaceae) (Voucher specimen for resin No. NPL-RE-20160521-5) at the location of $51^{\circ} 59^{\prime} 41.29^{\prime \prime} \mathrm{N} 5^{\circ} 48^{\prime} 57.25^{\prime \prime} \mathrm{E}$ in the forest area, 'De Bilderberg', of the Netherlands during April and June 2016 (early and late spring respectively).

All trees were between 55 and 60 years old at the time of sampling. Approximately $1.5 \mathrm{~mL}$ of resin were collected in $2 \mathrm{~mL}$-microtubes from each tree by drilling a $6 \mathrm{~cm}$ deep $\times 0.6 \mathrm{~cm}$ wide hole, diagonally upwards into the lower main trunk at $0.5 \mathrm{~m}$ above ground. In the case of Abies grandis resin it was obtained directly from the trees by cutting blisters on the trunk and squeezing out the resin into the microtubes. 


\section{2. ${ }^{1} H$ NMR analysis}

Pine resins $(15 \mathrm{mg})$ were dissolved in $1 \mathrm{~mL}$ of $\mathrm{CH}_{3} \mathrm{OH}-d_{4}$ containing $3.93 \mathrm{mM}$ hexamethyldisiloxane (HMDSO) as an internal standard, and sonicated for $1 \mathrm{~min}$. The solutions were centrifuged at 13,000 rpm and $300 \mu \mathrm{L}$ of the solutions were transferred into $3 \mathrm{~mm}$ NMR tubes for ${ }^{1} \mathrm{H}$ NMR analysis. The ${ }^{1} \mathrm{H}$ NMR analysis was performed in an AV- $600 \mathrm{MHz}$ NMR spectrometer (Bruker, Karlsruhe, Germany), operating at the ${ }^{1} \mathrm{H}$ NMR frequency of $600.13 \mathrm{MHz}$. For internal locking, $\mathrm{CH}_{3} \mathrm{OH}-\mathrm{d}_{4}$ was used. All ${ }^{1} \mathrm{H}$ NMR data consisted of 128 scans requiring $10 \mathrm{~min}$ and $26 \mathrm{~s}$ as the acquisition time using the parameters: $0.16 \mathrm{~Hz} /$ point, pulse width $(\mathrm{PW})=30^{\circ}(11.3 \mu \mathrm{s})$, and relaxation time of $1.5 \mathrm{~s}$. A pre-saturation sequence was used to suppress the residual water signal, using low power selective irradiation at $\mathrm{H}_{2} \mathrm{O}$ frequency during the recycle delay. The FIDs were Fourier transformed with an exponential line broadening of $0.3 \mathrm{~Hz}$. The resulting spectra were manually phased, baseline corrected and calibrated to HMDSO at $0.00 \mathrm{ppm}$ using TOPSPIN V. 3.0 (Bruker).

\subsection{GC-MS analysis}

Fresh resins were dissolved and diluted in $\mathrm{CH}_{2} \mathrm{Cl}_{2}$ to a final concentration of $2.0 \mathrm{mg} / \mathrm{mL}$. The solutions were analysed with a $7890 \mathrm{~A}$ gas chromatograph equipped with a 7693 automatic sampler and coupled to a 5975C mass single-quadrupole detector (Agilent, Folsom, CA, USA). Samples were separated using a DB-5 GC column ( $30 \mathrm{~m} \times 0.25 \mathrm{~mm}, 0.25 \mu \mathrm{m}$ film, J\&W Science, Folsom, CA, USA) and $\mathrm{He}(99.9 \%$ purity) as a carrier gas at a flow rate of $1 \mathrm{~mL} / \mathrm{min}$. The oven temperature was programmed starting at $40^{\circ} \mathrm{C}$ and increased to $150{ }^{\circ} \mathrm{C}$ at $5^{\circ} \mathrm{C} / \mathrm{min}$, then to $260^{\circ} \mathrm{C}$ at $7{ }^{\circ} \mathrm{C} / \mathrm{min}$ followed by a $3 \mathrm{~min}$ hold. The injector was set at $250^{\circ} \mathrm{C}$ and $1 \mu \mathrm{L}$ of sample was injected in split mode (10:1). The interface temperature was $280^{\circ} \mathrm{C}$, and the ion source and quadrupole temperature of the mass detector were $230{ }^{\circ} \mathrm{C}$ and $150{ }^{\circ} \mathrm{C}$, respectively. Ionisation energy in EI mode was $70 \mathrm{eV}$ and peaks were identified by comparison of their ion spectra with the NIST library (version 2008), or by comparison of their retention time and spectra with standard compounds. Tetradecane was used as the internal standard with a final concentration of $200 \mathrm{ng} / \mu \mathrm{L}$.

\subsection{High-performance thin-layer chromatography (HPTLC)}

Resin samples for HPTLC were dissolved in $\mathrm{CH}_{2} \mathrm{Cl}_{2}$ obtaining a final concentration of $2.0 \mathrm{mg} / \mathrm{mL}$ similarly to GC-MS analysis. Silica gel HPTLC plates $\left(20 \times 10 \mathrm{~cm}, \mathrm{~F}_{254}\right)$ were purchased from Merck (Darmstadt, Germany). A CAMAG HPTLC system equipped with an automatic TLC sampler (version 4), derivatiser (version 1.0 AT), TLC plate heater (version III), and TLC visualiser was used (CAMAG, Muttenz, Switzerland). A volume of $10 \mu \mathrm{L}$ of each solution was spotted in $6 \mathrm{~mm}$ bands. On each plate, 19 samples were applied at $10 \mathrm{~mm}$ from the bottom edge and $20 \mathrm{~mm}$ from the left and right borders of the plate. The distance between the bands was $8.8 \mathrm{~mm}$. A pool of all of the samples was applied on each plate as the QC (quality control) sample. The mobile phase for HPTLC analysis was a mixture of toluene-IPA$\mathrm{Et}_{2} \mathrm{O}(16: 1: 3, \mathrm{v} / \mathrm{v} / \mathrm{v})$. The chamber saturation time was $20 \mathrm{~min}$ and solvent migration distance was $80 \mathrm{~mm}$ from the application point. Developed HPTLC plates were sprayed with $2 \mathrm{~mL}$ of anisaldehyde$\mathrm{H}_{2} \mathrm{SO}_{4}$ solution using the automatic derivatiser and placed on a TLC plate heater at $100^{\circ} \mathrm{C}$ for $3 \mathrm{~min}$. Images of the derivatised plates were recorded using a TLC visualiser at $366 \mathrm{~nm}$.

\subsection{Data processing of analytical data and multivariate data analysis}

The NMR spectra were bucketed using AMIX 3.9.12 (Bruker BioSpin $\mathrm{GmbH}$, Rheinstetten, Germany). Bucket data was obtained by spectra integration at every $0.04 \mathrm{ppm}$ interval. The peak intensity of individual peaks was scaled to the total intensity recorded from $\delta 0.20$ to 10.02 .
Due to the residual signals of $\mathrm{D}_{2} \mathrm{O}$ and $\mathrm{CH}_{3} \mathrm{OH}-d_{4}$, regions $\delta$ 4.75-4.9 and $\delta 3.28-3.34$ were excluded from the analysis, respectively.

For GC-MS data acquisition, all total ion chromatograms were automatically integrated and peaks were identified using Mass Hunter Qualitative Analysis software version B.07.00 (Agilent). All of the identified signal intensities (190 compounds) were normalised to the internal standard $(200 \mu \mathrm{g} / \mathrm{mL}$ of tetradecane).

For data alignment and extraction from HPTLC plate images, rTLC (version 1.0) was used according to the method developed by Fichou et al. (2016). Dimensions used for image extraction were the same as those used for the sample application on the plates. For data integration, 128 units were used as the pixel width, and for band alignment parametric time warping was selected. The program produces integrated data from red, blue, green and grey channels., so that the first three channels focus on their corresponding colour, and the grey channel represents the mean of the first three channels. Therefore, to avoid a bias for the signals of the corresponding channel, the grey channel data was used to perform MVDA.

After data extraction, all signals were normalised to the corresponding pooled QC sample signals on each plate.

To identify the compounds corresponding to significant signals for group clustering, the bands of the respective $R_{f}$ values were scraped from the plates, extracted with $500 \mu \mathrm{L}$ of dichloromethane and ultrasonicated for $2 \mathrm{~min}$. After centrifugation at $3500 \mathrm{rpm}$, the supernatant was analysed by GC-MS using the same method used for the GC-MS analysis of resins.

Multivariate data analysis (MVDA) was performed using SIMCA P (v.14.1, Umeå, Sweden). Principal component analysis (PCA) and orthogonal projections to latent structures discriminant analysis (OPLSDA) were performed for ${ }^{1} \mathrm{H}$ NMR, GC-MS and HPTLC data, for which all of the raw data were scaled by Pareto except for the unit-variance (UV) scaling of OPLS-DA for GC-MS data with the two classes for the collection periods.

\section{Acknowledgements}

Mr. Luis Francisco Salomé-Abarca thanks the Mexican Scientific Council (CONACyT) for supporting a PhD scholarship (No. 410812). The authors greatly appreciate the contribution of Miss Alisa Hunter (Institute of Biology, Leiden University) for her valuable comments and suggestions, and Mr. Dick Bruynzeel from BCON Instrument (Sint Annaland, The Netherlands) for the technical support with the HPTLC analysis.

\section{Appendix A. Supplementary data}

Supplementary data related to this article can be found at https:// doi.org/10.1016/j.phytochem.2018.07.011.

\section{References}

De Alencar Filho, J.M.T., Araújo, L.D.C., Oliveira, A.P., Guimarães, A.L., Pacheco, A.G.M., Silva, F.S., Cavalcanti, L.S., Lucchese, A.M., Almeida, J.R.G.S., Araújo, E.C.C., 2017. Chemical composition and antibacterial activity of essential oil from leaves of Croton heliotropiifolius in different seasons of the year. Braz J. Pharm. 27, 440-444.

Dell, B., McComb, A.J., 1979. Plant resins - their formation, secretion and possible functions. Adv. Bot. Res. 6, 277-316.

Fichou, D., Ristivojević, P., Morlock, G.E., 2016. Proof-of-principle of rTLC, an opensource software developed for image evaluation and multivariate analysis of planar chromatograms. Anal. Chem. 88, 12494-12501.

Furtado, F.B., de Aquino, F.J.T., Nascimento, E.A., Martins, C.M., de Morais, S.A.L., Chang, R., Cunha, L.C.S., Leandro, L.F., Martins, C.H.G., Martins, M.M., da Silva, C.V., Machado, F.C., de Oliveira, A., 2014. Seasonal variation of the chemical composition and antimicrobial and cytotoxic activities of the essential oils from Inga laurina (Sw.) Willd. Molecules 19, 4560-4577.

Gallo, F.R., Multari, G., Pagliuca, G., Panusa, A., Palazzino, G., Giambenedetti, M., Petitto, V., Nicoletti, M., 2013. Bearberry identification by a multidisciplinary study on commercial raw materials. Nat. Prod. Res. 27, 735-742.

Gromski, P.S., Muhamadali, H., Ellis, D.I., Xu, Y., Correa, E., Turner, M.L., Goodacre, R., 2015. A tutorial review: metabolomics and partial least squares-discriminant analysis 
- a marriage of convenience or a shotgun wedding. Anal. Chim. Acta 879, 10-23.

Hakola, H., Tarvainen, V., Bäck, J., Ranta, H., Bonn, B., Rinne, J., Kulmala, M., 2006. Seasonal variation of mono- and sesquiterpene emission rates of Scots pine. Biogeosciences 3, 93-101.

Keefover-Ring, K., Linhart, Y.B., 2010. Variable chemistry and herbivory of ponderosa pine cones. Int. J. Plant Sci. 171, 293-302.

Koek, M.M., Jellema, R.H., van der Greef, J., Tas, A.C., Hankemeier, T., 2011. Quantitative metabolomics based on gas chromatography mass spectrometry: status and perspectives. Metabolomics 7, 307-328.

Kohyama, E., Chikumoto, T., Tada, H., Kitaichi, K., Horiuchi, T., Ito, T., 2016. Differentiation of the isomers of $N$-alkylated cathiones by GC-EI-MS-MS and LC-PDA. Anal. Sci. 32, 831-837.

Kusano, M., Zaitsu, K., Nakayama, H., Nakajima, J., Hisatsune, K., Moriyasu, T., Matsuta, S., Katagi, M., Tsuchihashi, H., Ishii, A., 2015. Positional isomer differentiation of synthetic cannabinoid JWH-081 by GC-MS/MS. J. Mass Spectrom. 50, 586-591.

Liu, X., Ahlgren, S., Korthout, H.A.A.J., Salomé-Abarca, L.F., Bayona, L.M., Verpoorte, R., Choi, Y.H., 2018. Broad range chemical profiling of natural deep eutectic solvent extracts using a high performance thin layer chromatography-based method. J. Chromatogr. A 1532, 198-207.

Martin, D., Tholl, D., Gershenzon, J., Bohlmann, J., 2002. Methyl jasmonate induces traumatic resin ducts, terpenoid resin biosynthesis, and terpenoid accumulation in developing xylem of Norway spruce stems. Plant Physiol. 129, 1003-1018.

Matias, E.F.F., Alves, E.F., Silva, M.K.N., Carvalho, V.R.A., Figueredo, F.G., Ferreira, J.V.A., Coutinho, H.D.M., Silva, J.M.F.L., Ribeiro-Filho, J., Costa, J.G.M., 2016. Seasonal variation, chemical composition and biological activity of the essential oil of Cordia verbenacea DC (Boraginaceae) and the sabinene. Ind. Crop. Prod. 87, 45-53.

Morlock, G.E., Ristivojevica, P., Chernetsova, E.S., 2014. Combined multivariate dat analysis of high-performance thin-layer chromatography fingerprints and direct analysis in real time massspectra for profiling of natural products like propolis. J. Chromatogr. A 1328, 104-112.

Mumm, R., Schrank, K., Wegener, R., Schulz, S., Hilker, M., 2003. Chemical analysis of volatiles emitted by Pinus sylvestris after induction by insect oviposition. J. Chem. Ecol. 29, 1235-1252.

Nicoletti, M., 2012. Nutraceutical and botanicals appeal for new analytical solutions. J.
Chromatogr. Separ. Tech. 3https://doi.org/10.4172/2157-7064.1000e103. 103. 3:e103.

Nicoletti, M., Petitto, V., Gallo, F.R., Multari, G., Federici, E., Palazzino, G., 2012. The modern analytical determination of botanicals and similar novel natural products by the HPTLC fingerprint approach. Stud. Nat. Prod. Chem. 37, 217-258.

Nicoletti, M., Toniolo, C., Murugan, K., 2013a. The HPTLC approach to metabolomic determination of neem products composition. Pharmacologyonline 3, 122-127.

Nicoletti, M., Toniolo, C., Gallo, F.R., Multari, G., 2013b. Traceability in multi-ingredient botanicals by HPTLC fingerprint approach. J. Planar. Chromatogr. 26, 243-247.

Phillips, M.A., Croteau, R.B., 1999. Resin-based defences in conifers. Trends Plant Sci. 4, 184-190.

Price, P.W., Bouton, C.E., Gross, P., McPheron, B.A., Thomp, J.N., Weis, A.E., 1980. Interactions among three trophic levels: influence of plants on interactions between insect herbivores and natural enemies. Annu. Rev. Ecol. Syst. 11, 41-65.

Raffa, K.F., Berryman, A.A., 1983. The role of host plant resistance in the colonization behavior and ecology of bark beetles (Coleoptera: scolytidae). Ecol. Monogr. 53, 27-49.

Rivas-Ubach, A., Hódar, J.A., Sardans, J., Kyle, J.E., Kim, Y.-M., Oravec, M., Urban, O., Guenther, A., Peñuelas, J., 2016. Are the metabolomic responses to folivory of closely related plant species linked to macroevolutionary and plant-folivore coevolutionary processes? Ecol. Evol. 6, 4372-4386.

Skakovskii, E.D., Tychinskaya, L.Yu, Gaidukevich, O.A., Kozlov, N.G., Klyuev, A.Yu, Lamotkin, S.A., Shpak, S.I., Rykov, S.V., 2008. NMR determination of the composition of balsams from scotch pine resin. J. Appl. Spectrosc. 75, 439-443.

Taft, S., Najar, A., Godbout, J., Bousquet, J., Erbilgin, N., 2015. Variations in foliar monoterpenes across the range of jack pine reveal three widespread chemotypes: implications to host expansion of invasive mountain pine beetle. Front. Plant Sci. 6, 342. https://doi.org/10.3389/fpls.2015.00342.

Toniolo, C., Nicoletti, M., Maggi, F., Venditti, A., 2014. HPTLC determination of chemical composition variability in raw materials used in botanicals. Nat. Prod. Res. 28, 119-126. https://doi.org/10.1080/14786419.2013.852546.

Witte, L., 1986. GC-ms methods for terpenoids. In: Linskens, H.F., Jackson, J.F. (Eds.), Gas Chromatography/Mass Spectrometry. Springer, Berlin, Heidelberg, pp. 134-145. 